\title{
Knowledge and willingness of physicians about deprescribing among older patients: a qualitative study
}

This article was published in the following Dove Press journal:

Clinical Interventions in Aging

\author{
Maha M AIRasheed' \\ Tariq M Alhawassil-3 \\ Alanoud Alanazi' \\ Nouf Aloudah' \\ Fowad Khurshid' \\ Mohammed Alsultan' \\ 'Department of Clinical Pharmacy, \\ College of Pharmacy, King Saud \\ University, Riyadh, Saudi Arabia; \\ ${ }^{2}$ Medication Safety Research Chair, \\ College of Pharmacy, King Saud \\ University, Riyadh, Saudi Arabia; \\ ${ }^{3}$ Pharmacy Services, King Saud \\ University Medical City, \\ Riyadh, Saudi Arabia
}

Purpose: This study aimed to explore the physician's knowledge and identify the perceived barriers that prevent family medicine physicians from engaging in deprescribing among older patients.

Methods: This qualitative study was designed and conducted using an interpretive theoretical approach. Purposive sampling was undertaken, whereby family medicine physicians of King Saud University Medical City (KSUMC), Riyadh, Saudi Arabia, were invited to participate in the study. The topic guidelines were designed to give the physicians the freedom to express their views on exploring their knowledge about deprescribing and to identify the perceived barriers and enablers that prevent them from engaging in the practice in older patients. The focus group discussions were conducted in English, audio-taped with permission, and transcribed verbatim. Each transcript was independently reviewed and coded separately to explore the themes and sub-themes.

Results: A total of 15 physicians participated in three focus group discussions. Their thematic content analysis identified 24 factors that facilitated or hindered deprescribing. The facilitators included cost-effectiveness and time effectiveness, side effects avoidance, clinical pharmacist's role, need for system(s) to help in applying deprescribing, and patient counseling/education. Similarly, barriers included lack of knowing the deprescribing term and process, patient comorbidities, risk/fear of conflict between physicians and clinical pharmacists, lack of documentation and communication, lack of time or crowded clinics, and patient resistance/acceptance.

Conclusion: The study identified several factors affecting family medicine physician's deprescribing behavior. The use of theoretical underpinning design helped to provide a comprehensive range of factors that can be directed when defining targets for intervention(s).

Keywords: deprescribing, barrier, enablers, polypharmacy

\section{Introduction}

Advancing age is associated with multiple chronic diseases, which finally lead to an increase in the prescription of medications. Global researchers have shown that polypharmacy (the prescription of multiple medications) is a worldwide issue and common among the elderly population. ${ }^{1,2}$ Use of multiple medication, particularly among the elderly, can cause considerable risk for medication error, nonadherence, and adverse drug-drug interactions. ${ }^{3,4}$ Several studies have reported that usage of a large number of medications is also associated with the risk of prescribing unnecessary or inappropriate medications. ${ }^{5-7}$ Furthermore, recent international data suggest that approximately one of the five prescriptions to elderly persons in primary care is inappropriate. ${ }^{8}$ The prevalence of inappropriate medication use (IMU) by the elderly people showed wide
Correspondence: Maha M AIRasheed Department of Clinical Pharmacy, College of Pharmacy, King Saud University, PO Box 2457, Riyadh II45I, Saudi Arabia Tel +966 II 4678707

Fax +966 II 4677480

Email mahalrasheed@ksu.edu.sa (c) (i) (5) 2018 AlRasheed et al. This work is published and licensed by Dove Medical Press Limited. The full terms of this license are available at https://www.dovepress.com/terms.php (c) $\mathrm{BY}$ and incorporate the Creative Commons Attribution - Non Commercial (unported, v3.0) License (http://creativecommons.org/licenses/by-nc/3.0/). By accessing the work you hereby accept the Terms. Non-commercial uses of the work are permitted without any further permission from Dove Medical Press Limited, provided the work is properly attributed. For permission for commercial use of this work, please see paragraphs 4.2 and 5 of our Terms (https://www.dovepress.com/terms.php). 
variations ranging from $11.5 \%$ to $62.5 \% .^{7}$ The use of potentially inappropriate medications (PIMs) among the elderly is a stern public health problem, as it is principally related to increased morbidity and mortality, which in turn may cause an increase in health care expenditures. ${ }^{9,10}$ Moreover, in a study of the Medical Expenditure Panel Survey in the United States, the total estimated health care expenditures related to the use of PIMs was $\$ 7.2$ billion. ${ }^{9}$ The high prevalence of PIMs and their significant predictors is a principal challenge in clinical practice and hence signifies the need for medication-monitoring systems. Although there are many guidelines available to guide prescribers in order to begin therapies that are safe and effective, there is a lack of knowledge pertaining to the cessation, reduction, or suspension of an inappropriate medication. ${ }^{11,12}$

The term deprescribing describes the process of withdrawing an inappropriate medication supervised by a health care professional with the goal of managing polypharmacy and improving outcomes. ${ }^{13}$ A number of tools exist to assist practitioners in deprescribing decisions. ${ }^{14-17}$ Scott et al have outlined steps involved in the deprescribing process. These include review of all medications, identification of inappropriate medications (with consideration of harms and benefits of medication use in the individual and in the setting of life expectancy and care goals), prioritization of medications for discontinuation, implementing a discontinuation regimen of medications (often with tapering), and closely monitoring of patients for improvement in outcomes or onset of adverse effects. ${ }^{17}$ A recent systematic review demonstrated, for example, that withdrawal of psychotropic drugs and benzodiazepines reduced the number of falls and improved cognition and psychomotor functioning. ${ }^{18} \mathrm{~A}$ randomized controlled study focusing on deprescribing in 146 frail inpatients reported the reduction in PIMs at discharge using the Screening Tool of Older People's Prescriptions (STOPP). ${ }^{19}$ Also, Reeve et $\mathrm{al}^{20}$ recently published a review of patient barriers and enablers to deprescribing and emphasized the importance of a patient-centered deprescribing process. Furthermore, a 2016 Cochrane review showed that inpatient medication reviews led by physicians, pharmacists, and other health care professionals resulted in a $27 \%$ reduction in emergency department visits, follow-up ranging from 30 days to 1 year. ${ }^{21}$ Hence, deprescribing is one approach to the rationalization of prescriptions to minimize risk and achieve better outcomes. However, many physicians seem hesitant to discontinue other physicians' prescriptions, resulting in additional polypharmacy, while other health care professionals regard this question as beyond their control. ${ }^{22}$
Therefore, it is pertinent to explore the physicians' knowledge and willingness to endorse appropriate deprescribing. In Saudi Arabia, demographic trends are changing continuously. The demographic predictions of the United Nations show that population aging in Saudi Arabia is entering a new phase and approaching its highest ever rate. The proportion of the elderly population aged 60 years and older is projected to increase from $3 \%$ in 2010 to $9.5 \%$ in 2035 and predicted to reach $18.4 \%$ by the end of $2050 .{ }^{23}$ Thus, the number of elderly patients with multiple comorbidities - and hence polypharmacy - will escalate in the next 15 years. Also, an earlier local study in 2004 at an ambulatory care setting in a military hospital has alluded to this problem and reported a total of $43.6 \%$ of the patients having filled a prescription of one PIM, while $18 \%$ had two PIMs and $38.4 \%$ had three or more PIMs. ${ }^{24}$ There are no published studies exploring the knowledge and willingness of physicians related to deprescribing in Saudi Arabia. For this reason, we have designed a study whose primary aim was to explore family physicians' (FPs) knowledge about deprescribing and explore enablers that facilitate deprescribing. The novel contribution of our research lies in its focus on the elderly population, where risks of prescribing unnecessary or inappropriate medications are the most likely. ${ }^{8}$ Besides, this study also explores the perceived barriers that prevent them from engaging in deprescribing for older patients. The secondary aim was to gather information regarding their willingness to endorse appropriate deprescribing among hospitals in Saudi Arabia.

\section{Methods}

\section{Study approach}

A qualitative study was designed and conducted using an interpretive theoretical approach. Focus groups were chosen as data collection methods since they are particularly useful when the aim is to gain different views on a specific topic. ${ }^{25}$

\section{Participants and setting}

Purposive sampling was adopted as it is a technique widely used in qualitative research for the identification and selection of individuals or groups of individuals who are especially knowledgeable and/or experienced with a phenomenon of interest. We identified the years of experience, position in the family medicine department, and gender as the criteria to be varied when inviting participants. These characteristics were identified to help in acquiring the richest possible information about deprescribing that would assist in targeting the most impactful intervention(s). The study was 
conducted in the Department of Medicine at the KSUMC, between October 2016 and December 2016. Accordingly, an invitational e-mail was sent to the Department, followed by personal contact for each interested physician who was matched to the required characteristic. All participants signed an informed consent, and the study was performed in accordance with the regulations laid down by the Institutional Review Board (IRB) of the College of Pharmacy, King Saud University, Riyadh, Saudi Arabia, in compliance with the principles of the Declaration of Helsinki (http://www.wma. net/en/30publications/10policies/b3/index.html).

\section{Data collection}

A focus group guide was developed by the study team. The questions were derived from Michie et al's ${ }^{26}$ consensus study and modified to fit the topic. These questions were developed by health psychologists, health service researchers, and clinicians from 14 domains that help researchers understand the health care provider behavior and how to change it. The 14 domains were developed using the most relevant 33 behavioral change theories that explain health behavior and related changes. A topic guide was designed to give the FPs the freedom to express their views on exploring their knowledge about the concept and to identify the perceptive barriers that prevent them from engaging in deprescribing in older patients and the enablers that facilitate the process, as well as gathering information regarding their willingness to endorse it appropriately.

The focus group guide was piloted with five family medicine residents. It was used as a general guide, and probes such as "Could you explain that further?" and "Would you give me an example?" were used to access more in-depth information and discussion. A total of 15 physicians attended the three focus groups. The mean age of these 15 participants was 38 years (range $30-55$ years), the majority of whom were female. The three focus groups were conducted lasting for 40-60 minutes. Each focus group consisted of five physicians working in the Department of Medicine as a family medicine specialist, resident, or general practitioner. They were conducted in English, audio-taped with permission, and transcribed verbatim. Theme saturation was approximately achieved during the second focus group, and a third focus was conducted to confirm the saturation.

\section{Data analysis}

As the focus groups progressed, data were analyzed after each group to develop preliminary codes to identify important and new emerging information. Each transcript was independently reviewed and coded separately as AA and NA to explore the themes and subthemes, respectively. Thematic content analysis was undertaken. The disagreement was $20 \%$, calculated as the number of quotations AA and NA agreed upon compared to those that they did not agree upon. Disagreements were resolved by discussions led by a participant designated TA and the three focus group analyses reviewed by another referred to as MA.

\section{Ethical approval}

The study was approved by the KSUMC's IRB. It was based on the usual ethical principles, such as each participant's right to refuse to participate in the study and to withdraw at any time, as well as respect for all participants and protection of their privacy.

\section{Results \\ Knowledge and willingness about deprescribing FPs expressed ignorance}

To explore the knowledge on the concept among FPs, we asked participants about the definition of deprescribing. Most of them were unaware of the term. This study also showed that the participants were willing to cease a medication that they thought their patients no longer required. However, the majority of them were unsure exactly as to how to do this. Some of the FPs acknowledged that they knew it and performed it but not as deprescribing.

What do you mean by deprescribing? The term? I don't know. [D5 FG1]

Yes, its first time to hear about it. We don't have any knowledge about this. [D2 FG3]

What we have actually from the literature and guidelines is the process in how to taper doses and how reducing doses and stopping medication aaahhha and discontinuation but the term itself I don't really. So far am not aware. [D1 FG3]

\section{Deprescribing barriers}

The research findings show that the participants experienced several barriers that prevent them from engaging in deprescribing. Table 1 includes quotes highlighting these barriers. The findings are elaborated further below.

\section{Lack of knowledge}

The FPs lacked the knowledge of deprescribing in a safe and effective manner. 
Table I Barriers and related quotations hindering deprescribing

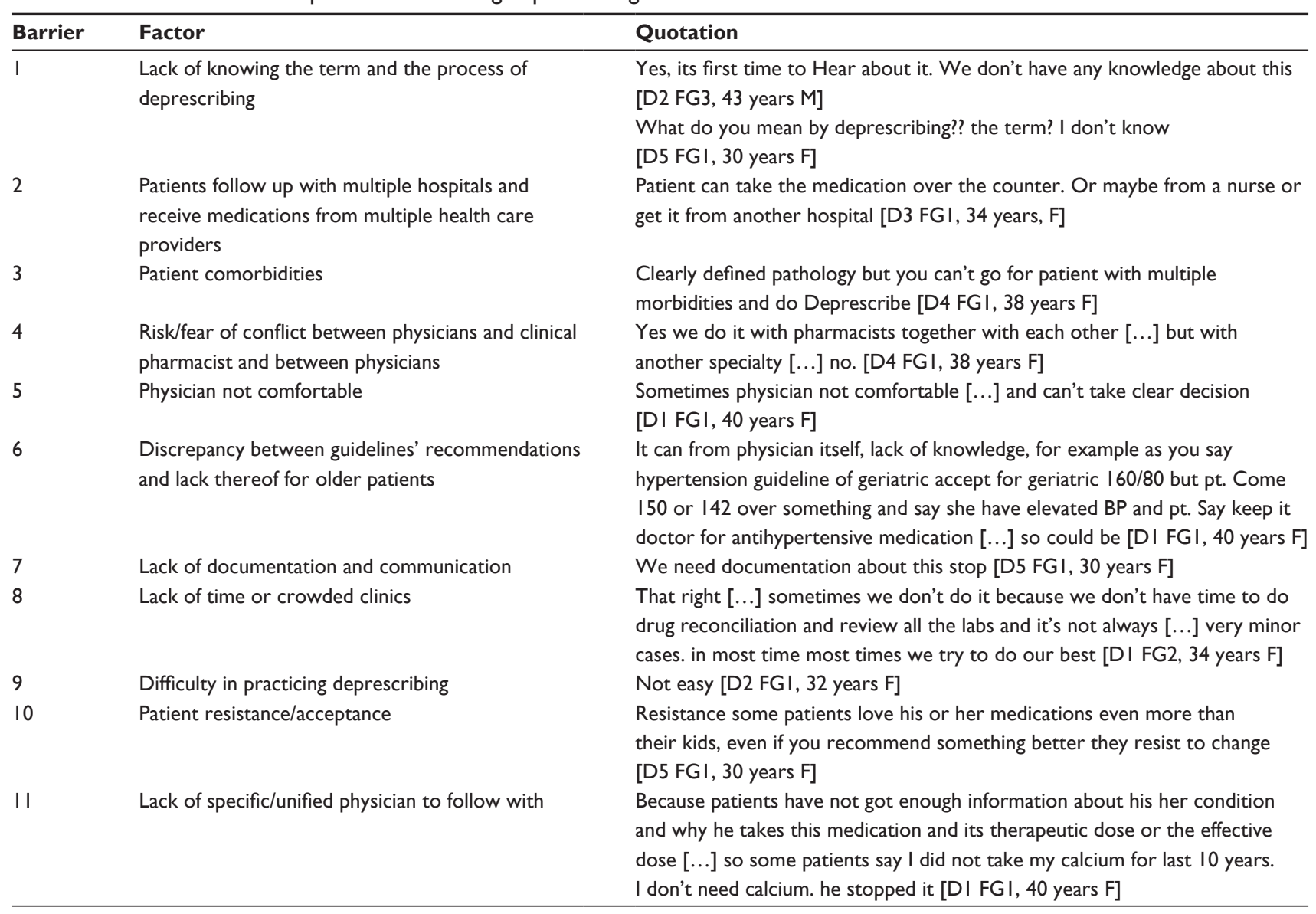

Abbreviations: D, consultant participated in each focus group; F, female; FG, focus group; M, male.

Deprescribing - I am not aware as the term. [D1 FG3]

Sometimes physician is not comfortable $[\ldots]$ and can't

take a clear decision. [D1 FG1]

\section{Patient resistance/acceptance}

Some of the FPs in our study felt that patients may not always be willing to stop or change medicines they have been taking for a long time, despite the physician's recommendations.

Some patients love his or her medications even more than their kids, even if you recommend something better they resist to change. [D5 FG1]

Patient takes Fosamax for 6 years and in her data, nothing explains why she is on it, even osteopenia [...] no history of it. So I ask her no need for the use of it and she became very angry $[. .$.$] why do you want to do it? I told her$ you don't have any reason any disease, nothing statement not understandable [...]. [D4 FG2]

\section{Other prescribers/patient comorbidities}

The FPs in our study were reluctant to deprescribe medications that had been prescribed by a specialist or another practitioner. This study also illustrates that FPs feel pressured into continuing the prescription of certain medicines initiated by specialists.

Sometimes the medication is prescribed under another treating team, so I ignore it. [D2 FG1]

\section{Lack of documentation and communication}

The FPs highlighted their lack of detail as to why and for how long the medicine was taken.

We don't have an indication; no indication why the patient was on it or why the patient stops it. [D1 FG2]

We need documentation about this stop. [D5 FG1]

\section{Lack of physician time or crowded clinic}

The FPs reported lack of time as one of the barriers, as time constraints may stop them from addressing all of the patients' concerns, which may lead to suboptimal medicine management.

Sometimes we don't do it because we don't have time to do drug reconciliation and review all the labs and it's not 
always $[. .$.$] very minor cases. In most time we try to do$ our best [...]. [D1 FG2]

\section{Facilitators to deprescribing}

Several possible deprescribing facilitators came to light, which can serve as a platform for improving medication management in older people (Table 2). There was strong agreement among respondents that an easy-to-find online database of guidelines would facilitate deprescribing. Respondents generally highlighted that clear and transparent communication between physicians and health care providers, screening of each patient for the need of deprescribing, patient counseling and education on the subject would also facilitate the use of deprescribing in practice.

\section{Medication adherence, cost-effectiveness, and side effects avoidance}

The FPs felt that deprescribing may improve patient medication adherence, reduce/discontinue the number of medications taken (cost-effectiveness) and therefore reduce possible side effects.

To increase the adherence of medication [...] maybe if the number of the medication was decreased $[\ldots]$ the adherence toward medication will be more. [D2 FG1]
Yes, cost-effectiveness [...] If I make discontinuation for a medication and discharge the patient from clinic it will decrease the cost. [D2 FG1]

I heard also about a study that they mention that the third cause of death is the drug that we are prescribing either drug interaction or side effect or overdose [...] it's the third cause of death. [D2 FG2]

\section{Role of clinical pharmacist}

The FPs perceived that physicians and pharmacists have worked together using a multidisciplinary approach to reduce polypharmacy and IMU in older people by carrying out comprehensive medicine reviews. They were positive about the potential for interprofessional partnerships.

Yes, physician knows that he has to stop but doesn't know how [...] so he can ask the clinical pharmacist. [D1 FG3]

\section{A need for technology and/or a system: better communication between physicians and health care providers}

Clear and transparent communication is essential between physicians and other health care providers.

I feel that must have a chat in the system between the physicians. [D2 FG1]

Table 2 Facilitators and related quotations facilitating deprescribing

\begin{tabular}{|c|c|c|}
\hline Facilitators & Factor & Quotation \\
\hline I & Avoid side effect & $\begin{array}{l}\text { I heard also about a study that they mention that the third cause of death is the drug } \\
\text { that we are prescribing either drug interaction or side effect or overdose [...] it's the } \\
\text { third cause of death. [D2 FG2, } 50 \text { years F] }\end{array}$ \\
\hline 2 & $\begin{array}{l}\text { Increase patient adherence and medication } \\
\text { outcomes }\end{array}$ & $\begin{array}{l}\text { To increase the adherence to medication. Maybe if the number of the medication was } \\
\text { decreased }[\ldots] \text { the adherence toward medication will be more [D2 FGI, } 32 \text { years F] }\end{array}$ \\
\hline 3 & Cost and time effectiveness & $\begin{array}{l}\text { Yes, cost-effectiveness }[\ldots] \text { If I make discontinuation for a medication and discharge } \\
\text { the patient from the clinic it will decrease the discharge time }[\ldots] \text { [D2 FGI, } 32 \text { years F] }\end{array}$ \\
\hline 4 & Avoid drug interactions & For drug interaction for some medication [DI FGI, 40 years F] \\
\hline 5 & $\begin{array}{l}\text { Ambiguity/uncertainty of who is responsible } \\
\text { for conducting deprescribing }\end{array}$ & Who do Deprescribing? I think physician not understandable [D4 FGI, 38 years F] \\
\hline 6 & Role of clinical pharmacist & Part of implementation is to integrate with clinical pharmacist [DI FGI, 40 years, F] \\
\hline 7 & $\begin{array}{l}\text { A need for technology and/or a system } \\
\text { involvement to help in the application of } \\
\text { deprescribing }\end{array}$ & $\begin{array}{l}\text { Or part here for example in eSiHi [health system in } \mathrm{KKUH} \text { ] for a clinical pharmacist, } \\
\text { I sent to the pharmacists the request and I get immediate answer, so we have an online } \\
\text { service [DI FG2, } 34 \text { years F] }\end{array}$ \\
\hline 8 & $\begin{array}{l}\text { Availability of medication and medication } \\
\text { restriction policies }\end{array}$ & $\begin{array}{l}\text { Wait there is one thing I did not understand is it ok }[\ldots] \text { pantoprazole is not restricted } \\
\text { by pharmacy but esomeprazole is restricted }[\ldots] \text { I know that pantoprazole is expensive } \\
\text { than esomeprazole }[\ldots] \text { so why its restricted? [D5 FG3, } 4 \text { I years } \mathrm{M}]\end{array}$ \\
\hline 9 & Availability of resources/support & $\begin{array}{l}\text { Availability of evidence }[\ldots] \text { make a guideline. for example, cross-reaction between } \\
\text { medication. I think its possible [D5 FGI, } 30 \text { years F] }\end{array}$ \\
\hline 10 & Need for special geriatric clinic & We need to have geriatric clinic [DI FGI, 40 years F] \\
\hline II & $\begin{array}{l}\text { Screen each patient for the need of } \\
\text { deprescribing }\end{array}$ & $\begin{array}{l}\text { For each patient should be reviewed if he/she need this medication or not [DI FGI, } \\
40 \text { years F] }\end{array}$ \\
\hline 12 & Drug reconciliation & $\begin{array}{l}\text { So here the process of Deprescribing must omit to start with drug reconciliation } \\
\text { [DI FG2, } 34 \text { years F] }\end{array}$ \\
\hline 13 & Patient counseling/education & Given an education to the patient [D3 FG3, 55 years M] \\
\hline
\end{tabular}

Abbreviations: $D$, consultant participated in each focus group; $F$, female; FG, focus group; $M$, male. 
I sent to the pharmacists the request and I get immediate answer $[\ldots]$ so we have an online service. [D1 FG2]

\section{Screening each patient for the need of deprescribing}

Each patient should be reviewed if he/she need this medication or not. [D1 FG1]

\section{Patient counseling/education}

In the present study, the FPs also highlighted the need for improving patients' awareness on such issues.

Given an education to the patient. [D3 FG3]

\section{Discussion}

Our study identified a range of prescriber-reported barriers and/or enablers to deprescribing. In this study, FPs, in general, feel that they do not possess sufficient knowledge and education to deprescribe medications for patients. This is consistent with findings from other studies. ${ }^{27,28}$ Implementation of an educational approach that endows FPs with the knowledge to deprescribe and a forum for discussions about the subject matter might be one way to overcome this barrier. ${ }^{29}$

Multimorbidity is a common occurrence in old age people. Hence, patients are often prescribed multiple medicines by multiple providers. Also, sometimes there is a perceived lack of communication between physicians and other specialists concerning their patients' medication. It was apparent in our study that the participating FPs expressed reluctance to interfering with medications that had previously been prescribed by another medical specialist, resulting in further polypharmacy. Our finding is in conformity with the findings of Palagyi et $\mathrm{al}^{28}$ and Wallis et al. ${ }^{30}$ This may happen as a result of the physicians not knowing the original indication for the medication and finding it too time-consuming to consult the original prescriber, which might reduce treatment quality. ${ }^{31,32}$ As indicated by the physicians in our study, sometimes the resistance to deprescribing comes from the patient, which becomes a barrier to medication cessation. Similar limitations were also reported in other international deprescribing studies. ${ }^{27,33}$ Providing information to patients about deprescribing of PIMs can reduce unnecessary adverse reactions and hence undue medical costs. This ultimately helps to reduce their decisional conflict. However, in contrast to our findings of prescriber perceptions, several studies on patient perceptions echoed that older adults are willing to have one or more of their medications stopped. ${ }^{11,34,35}$

In our study, many participants also cited time constraints as a barrier, since it prevents physicians from reviewing medicine lists for older people. This is consistent with findings from other studies. ${ }^{28}$ Pharmacist involvement in a multidisciplinary team to review medicines and to suggest possible medications to be deprescribe may be useful in these instances. ${ }^{36,37}$

To our knowledge, this study is the first qualitative exploration of family medicine physician perceptions of deprescribing among older patients in Saudi Arabia. Our research findings may contribute to the growing body of literature on physicians' views on the barriers to and enablers of deprescribing. It is, however, important to emphasize that the observations of our study are not necessarily representative of all family medicine physicians, as it was conducted in a tertiary referral academic hospital. Therefore, our findings need to be quantified in a more representative sample of family medicine physicians and other health care professionals actively involved in treating the frail elderly. Confirmation of our findings will contribute to the development of strategies to overcome the barriers found in this study.

Moreover, there is a wide variation in the health care system in different countries. This variation can be due to its governance, overall design, content, and management of health systems. It is well documented from the literature that deprescription is likely to be dependent on sociocultural conditions or to the country in which the study was conducted, because medication-taking behavior as well as beliefs about medications can vary depending on cultural background as well as country characteristics. ${ }^{40}$ Saudi Arabia is considered a developing country and is ranked as 26th among 190 countries in terms of its health care system. ${ }^{38}$ The Saudi government provides free medical care to all Saudi citizens and expatriates working in public sector through public health care facilities. In the Saudi health care system, the entire decision-making is centralized. The health care sector is primarily managed by the government through the Ministry of Health (MOH) and the number of semipublic organizations who specifically operate hospitals and medical services for their employees. At present, the $\mathrm{MOH}$ is a major financer and provider of government-based health care services in the country with approximately 274 hospitals, encompassing 41,835 beds and 2,325 primary health care (PHC) centers making it $60 \%$ of overall health services in the country. ${ }^{39}$ The health care system via the government bodies controls about 44 hospitals with an accommodation of 11,581 beds in total. In addition, private sector operators in Saudi Arabia play a key role in providing quality health care services in the Kingdom. They provide health care services for a fee through 152 hospitals and accounts for $24.6 \%(17,428)$ of 
the total hospital beds. ${ }^{39}$ Accordingly, these conditions are likely to influence variable affecting deprescribing differently from those prevailing in health care systems such as in a European or North American setting, where patient care management follows particular sets of pathways. Hence, the results of this study may not be applicable to some other different settings.

\section{Conclusion}

The results of this study highlighted the level of understanding of family medicine physicians about deprescribing in Saudi Arabia. There is a need for more education to both family medicine physicians and patients to achieve better conditions for the deprescribing practice. The study identified several factors affecting family medicine physicians' deprescribing behavior. The use of theoretical underpinning design helped to provide a comprehensive range of factors that can be implemented when defining targets for an intervention(s). Furthermore, systematic intervention development and testing are required to choose and prioritize the most promising interventions to change FP's deprescribing behavior.

\section{Acknowledgment}

The authors would like to extend their sincere appreciation to the Vice Deanship of Research Chairs, King Saud University, Riyadh, Saudi Arabia, for the financial support of this research.

\section{Disclosure}

The authors report no conflicts of interest in this work.

\section{References}

1. Hajjar ER, Cafiero AC, Hanlon JT. Polypharmacy in elderly patients. Am J Geriatr Pharmacother. 2007;5(4):345-351.

2. Nobili A, Licata G, Salerno F, et al. Polypharmacy, length of hospital stay, and in-hospital mortality among elderly patients in internal medicine wards. The REPOSI study. Eur J Clin Pharmacol. 2011;67(5): 507-519.

3. Frazier SC. Health outcomes and polypharmacy in elderly individuals: an integrated literature review. J Gerontol Nurs. 2005;31(9):4-11.

4. Dequito AB, Mol PG, van Doormaal JE, et al. Preventable and nonpreventable adverse drug events in hospitalized patients: a prospective chart review in the Netherlands. Drug Saf. 2011;34(11):1089-1100.

5. Fialova D, Topinkova E, Gambassi G, et al. Potentially inappropriate medication use among elderly home care patients in Europe. JAMA. 2005;293(11):1348-1358.

6. Aparasu RR, Mort JR. Inappropriate prescribing for the elderly: beers criteria-based review. Ann Pharmacother. 2000;34(3):338-346.

7. Guaraldo L, Cano FG, Damasceno GS, Rozenfeld S. Inappropriate medication use among the elderly: a systematic review of administrative databases. BMC Geriatr. 2011;11:79.

8. Opondo D, Eslami S, Visscher S, et al. Inappropriateness of medication prescriptions to elderly patients in the primary care setting: a systematic review. PLoS One. 2012;7(8):e43617.
9. Fu AZ, Jiang JZ, Reeves JH, Fincham JE, Liu GG, Perri M 3rd. Potentially inappropriate medication use and healthcare expenditures in the US community-dwelling elderly. Med Care. 2007;45(5):472-476.

10. Stock1 KM, Le L, Zhang S, Harada AS. Clinical and economic outcomes associated with potentially inappropriate prescribing in the elderly. $\mathrm{Am}$ J Manag Care. 2010;16(1):e1-e10.

11. Reeve E, Wiese MD, Hendrix I, Roberts MS, Shakib S. People's attitudes, beliefs, and experiences regarding polypharmacy and willingness to Deprescribe. J Am Geriatr Soc. 2013;61(9):1508-1514.

12. Garfinkel D, Mangin D. Feasibility study of a systematic approach for discontinuation of multiple medications in older adults: addressing polypharmacy. Arch Intern Med. 2010;170(18):1648-1654.

13. Reeve E, Gnjidic D, Long J, et al. A systematic review of the emerging definition of "deprescribing" with network analysis: implications for future research and clinical practice. Br J Clin Pharmacol. 2015;80(6): $1254-1268$.

14. The American Geriatrics Society 2012 Beers Criteria Update Expert Panel. American Geriatrics Society updated Beers Criteria for potentially inappropriate medication use in older adults. J Am Geriatr Soc. 2012; 60:616-631.

15. Gallagher P, Ryan C, Byrne S, Kennedy J, O'Mahony D. STOPP (Screening Tool of Older Person's Prescriptions) and START (Screening Tool to Alert doctors to Right Treatment). Consensus validation. Int J Clin Pharmacol Ther. 2008;46(2):72-83.

16. Spinewine A, Dumont C, Mallet L, et al. Medication appropriateness index: reliability and recommendations for future use. $J$ Am Geriatr Soc. 2006;54(4):720-722.

17. Scott IA, Hilmer SN, Reeve E, et al. Reducing inappropriate polypharmacy: the process of deprescribing. JAMA Intern Med. 2015;175(5): $827-834$.

18. Iyer S, Naganathan V, McLachlan AJ, Le Couteur DG. Medication withdrawal trials in people aged 65 years and older: a systematic review. Drugs Aging. 2008;25(12):1021-1031.

19. Dalleur O, Boland B, Losseau C, et al. Reduction of potentially inappropriate medications using the STOPP criteria in frail older inpatients: a randomised controlled study. Drugs Aging. 2014;31(4):291-298.

20. Reeve E, To J, Hendrix I, Shakib S, Roberts MS, Wiese MD. Patient barriers to and enablers of deprescribing: a systematic review. Drugs Aging. 2013;30(10):793-807.

21. Christensen M, Lundh A. Medication review in hospitalised patients to reduce morbidity and mortality. Cochrane Database Syst Rev. 2016;2:CD008986.

22. Kouladjian L, Gnjidic D, Reeve E, Chen TF, Hilmer SN. Health care practitioners' perspectives on deprescribing anticholinergic and sedative medications in older adults. Ann Pharmacother. 2016;50(8):625-636.

23. United Nations [webpage on the Internet]. World Population Prospects: The 2012 Revision. 2012. Available from: http://esa.un.org/unpd/wpp/ unpp/panel_indicators.htm. Accessed January 1, 2018.

24. Al-Omar HA, Al-Sultan MS, Abu-Auda HS. Prescribing of potentially inappropriate medications among the elderly population in an ambulatory care setting in a Saudi military hospital: trend and cost. Geriatr Gerontol Int. 2013;13(3):616-621.

25. Kitzinger J. Qualitative research. Introducing focus groups. BMJ. 1995;311(7000):299-302.

26. Michie S, Johnston M, Abraham C, et al. Making psychological theory useful for implementing evidence based practice: a consensus approach. Qual Saf Health Care. 2005;14(1):26-33.

27. Ailabouni NJ, Nishtala PS, Mangin D, Tordoff JM. Challenges and enablers of deprescribing: a general practitioner perspective. PLoS One. 2016;11(4):e0151066.

28. Palagyi A, Keay L, Harper J, et al. Barricades and brickwalls - a qualitative study exploring perceptions of medication use and deprescribing in long-term care. BMC Geriatr. 2016;16:15.

29. Bolmsjö BB, Palagyi A, Keay L, Potter J, Lindley RI. Factors influencing deprescribing for residents in Advanced Care Facilities: insights from General Practitioners in Australia and Sweden. BMC Fam Pract. 2016;17(1):152. 
30. Wallis KA, Andrews A, Henderson M. Swimming against the tide: primary care physicians' views on deprescribing in everyday practice. Ann Fam Med. 2017;15(4):341-346.

31. Anderson K, Stowasser D, Freeman C, Scott I. Prescriber barriers and enablers to minimising potentially inappropriate medications in adults: a systematic review and thematic synthesis. BMJ Open. 2014;4(12): e006544.

32. Harriman K, Howard L, McCracken R. Deprescribing medication for frail elderly patients in nursing homes: a survey of vancouver family physicians. BC Med J. 2014;56(9):436-441.

33. Schuling J, Gebben H, Veehof LJ, Haaijer-Ruskamp FM. Deprescribing medication in very elderly patients with multimorbidity: the view of Dutch GPs. A qualitative study. BMC Fam Pract. 2012;13:56.

34. Qi K, Reeve E, Hilmer SN, Pearson SA, Matthews S, Gnjidic D. Older peoples' attitudes regarding polypharmacy, statin use and willingness to have statins deprescribed in Australia. Int J Clin Pharm. 2015;37(5): 949-957.

35. Galazzi A, Lusignani M, Chiarelli MT, et al. Attitudes towards polypharmacy and medication withdrawal among older inpatients in Italy. Int J Clin Pharm. 2016;38(2):454-461.
36. Walsh KA, O'Riordan D, Kearney PM, Timmons S, Byrne S. Improving the appropriateness of prescribing in older patients: a systematic review and meta-analysis of pharmacists' interventions in secondary care. Age Ageing. 2016;45(2):201-209.

37. Marvin V, Ward E, Poots AJ, Heard K, Rajagopalan A, Jubraj B. Deprescribing medicines in the acute setting to reduce the risk of falls. Eur J Hosp Pharm Sci Pract. 2017;24(1):10-15.

38. WHO [webpage on the Internet]. The World Health Report 2000-World Health Organization Assesses the World's Health Systems: Improving Performance. Available from: http://www.who.int/whr/2000/ media_centre/press_release/en/. Accessed July 1, 2017.

39. Ministry of Health. Statistical Year Book, 2016. Kingdom of Saudi Arabia. Saudi Arabia: 2016. Available from: https://www.moh.gov. sa/en/Ministry/Statistics/book/Documents/Statistical-Yearbook-1437H. pdf. Accessed July 1, 2017.

40. Horne R, Graupner L, Frost S, Weinman J, Wright SM, Hankins M. Medicine in a multi-cultural society: the effect of cultural background on beliefs about medications. Soc Sci Med. 2004;59:1307-1313.
Clinical Interventions in Aging

\section{Publish your work in this journal}

Clinical Interventions in Aging is an international, peer-reviewed journal focusing on evidence-based reports on the value or lack thereof of treatments intended to prevent or delay the onset of maladaptive correlates of aging in human beings. This journal is indexed on PubMed Central, MedLine,

\section{Dovepress}

CAS, Scopus and the Elsevier Bibliographic databases. The manuscript management system is completely online and includes a very quick and fair peer-review system, which is all easy to use. Visit http://www.dovepress. com/testimonials.php to read real quotes from published authors. 